
representante e representado. Oikos: Família e Sociedade em Debate, v. 29, n. 1 , p. $125-145,2018$.

DOI: http://dx.doi.org/10.31423/2236-8493.v29i1.358

\title{
A representação no Conselho Municipal de Assistência Social de Viçosa-MG: da autorização à relação representante e representado
}

\section{Representation in the Municipal Council of Social Assistance of Viçosa-MG: authorization to representative and represented relationship}

\author{
Jordana de Souza Morais ${ }^{1}$ \\ Amélia Carla Sobrinho Bifano ${ }^{2}$ \\ Maria das Dores Saraiva de Loreto ${ }^{3}$ \\ Edson Arlindo Silva ${ }^{4}$
}

\section{Resumo}

Este artigo busca analisar as características e os desafios de representatividade do Conselho Municipal de Assistência Social (CMAS) de Viçosa-MG, no período de cinco meses, considerando a legitimação da autorização e as relações entre representantes e representados. Os resultados mostraram que a forma de escolha utilizada pelas entidades para a seleção dos conselheiros é feita, preferencialmente, por meio de indicação, sem interferência dos representados. Os relatos dos conselheiros evidenciaram fragilidade na representação e no vínculo entre representantes e representados. Além disso, os temas que mais aparecem na pauta evidenciam que o poder público tem maior capacidade de agenda, sendo as deliberações mais pontuais, com prevalência de questões administrativas. Assim, conclui-se que ainda é um desafio para o CMAS o fortalecimento das relações de representatividade, de forma que os conselheiros defendam os interesses do coletivo, o que exige maior proximidade e identificação dos representantes com seus representados, de forma a atender suas necessidades e demandas.

Palavras-chaves: Representação; Representatividade; Interesse Coletivo.

\begin{abstract}
This article seeks to analyze the representation of characteristics and challenges of the Municipal Council of Social Assistance (MCSA) of Viçosa-MG, in the period of 5 (five) months, considering the legitimacy of the authorization and the relationship between representatives and represented. The results showed that the choice used by the entities for the selection of the counselors is made, preferably, by an indication without interference of represented. The reports of the counselors showed a weakness representation and link between representatives and represented. Moreover, the issues that most appear on the agenda show that the government has a larger capacity of agenda, which in the resolutions are most specific, with a prevalence of administrative issues. Wherefore, it is concluded that the strengthening of relationships' representation is still a challenge for the MCSA, so that counselors defend the interests of the collective, which requires a greater proximity and an identification of representatives with their constituents in order to meet their needs and demands.
\end{abstract}

Keywords: Representation; Representativeness; Collective interest.

\footnotetext{
1 Mestra em Economia Doméstica e Graduada em Economia Doméstica pela Universidade Federal de Viçosa. E-mail: jordana.moraiis@gmail.com

${ }^{2}$ Doutora em Engenharia de Produção pela Escola Politécnica da USP. Professora do Programa de Pós-Graduação em Economia Doméstica da Universidade Federal de Viçosa. E-mail: abifano@ufv.br

${ }^{3}$ Doutora em Economia Aplicada pela Universidade Federal de Viçosa. Professora do Programa de Pós-Graduação em Economia Doméstica da Universidade Federal de Viçosa. E-mail: mdora@ufv.br

${ }^{4}$ Doutor em Administração pela Universidade Federal de Lavras. Professor da Universidade Federal de Uberlândia. E-mail: edsonasilva@ufu.br
} 


\section{INTRODUÇÃO}

Os Conselhos Gestores de Políticas Públicas são exemplos de reconfiguração nas práticas políticas no Brasil, enquanto espaços que trazem novos desafios e perspectivas para a teoria democrática, não só pelo fato de terem se tornado espaços institucionalizados de participação, mas também por instituírem novas práticas de representação política (SANTOS, 2002).

Nesse sentido, não é pelo fato de os Conselhos Gestores de Políticas Públicas serem participativos, isto é, terem como fundamento a participação da sociedade civil na formulação e implementação das políticas públicas, que, em seus mecanismos, não seja necessária a representação desse segmento por sujeitos representantes. Na perspectiva clássica do autor Pitkin (1967), representação política diz respeito a "agir em nome de", um sujeito se torna representante para atuar em nome do segmento que representa.

Isso se deve ao fato de que a sociedade contemporânea é caracterizada pela diversidade e complexidade, com crescimento desordenado das cidades e multiplicação dos problemas e desigualdades sociais. Resultado disso é que as soluções se tornam mais difíceis de serem alcançadas, o que impossibilita a participação de todos os cidadãos nas deliberações, prevalecendo a democracia por meio da representação.

Uma das características da democratização pela representação é a forma como os conselheiros são escolhidos por sua entidade, para participar dos Conselhos Gestores de Políticas Públicas. Nesse sentido, nesses espaços de participação, os representantes podem ser escolhidos de maneiras diferentes e variadas, em forma de indicação ou eleição ou outras formas específicas, que podem ser determinadas e utilizadas por cada entidade.

Embora a forma de escolha dos conselheiros do Conselho Municipal de Assistência Social (CMAS) seja importante para a legitimidade da sociedade civil, a representação não pode ser considerada somente por esse processo de autorização. É preciso considerar, também, a relação entre representante e representado; ou seja, a relação estabelecida entre os conselheiros da sociedade civil e as entidades que representam.

Assim, quando o representante se coloca no papel de falar em nome de outros, ele deve representar a opinião do coletivo, dos sujeitos que representa e não a sua opinião individual. Para isso, ele precisa desenvolver maneiras de se informar sobre as opiniões do seu segmento, sobre o tema a ser debatido e decidido, levando até ele as informações sobre as discussões das quais 
participa, prestando contas da sua atuação. Contudo, os representados também precisam subsidiar os representantes com informações, opiniões e discussões realizadas naquele grupo e cobrá-lo quanto à sua atuação. $O$ representante deve defender os interesses do seu segmento, sem deixar de reconhecer as necessidades e demandas de outros segmentos (SERAFIM; SANTOS, 2009).

No entanto, a qualidade dessa representação é um grande desafio para o CMAS, pois, como bem explica Dowbor et al. (2008), a falta de representatividade é comum e pode deslegitimar os conselhos, enfraquecendo seu papel na definição das políticas públicas frente aos outros espaços, ou pode resultar na elaboração de políticas que não contemplem as demandas dos setores que representam.

Nesse sentido, diante das questões apresentadas, este artigo pretendeu analisar as características e desafios de representatividade do Conselho Municipal de Assistência Social (CMAS) de Viçosa-MG, considerando a legitimação da autorização e das relações entre representantes e representados. Especificamente: identificar as formas de autorização ${ }^{5}$ dos representantes, ou seja, como está sendo legitimada a autorização dada aos conselheiros do CMAS; analisar a relação do representante com o representado, isto é, como se dá a relação do conselheiro com a entidade que representa, examinando se há discussão da pauta antes da reunião, bem como se há a prestação de contas após as reuniões, no que diz respeito às políticas de assistência social; identificar os temas inseridos nas pautas.

\section{PROCEDIMENTOS METODOLÓGICOS}

Para analisar as características e conflitos de representatividade do Conselho Municipal de Assistência Social de Viçosa-MG, foi utilizada a técnica da entrevista aberta (Apêndice A) e a observação direta e registro das falas (Apêndice B), no decorrer das reuniões do Conselho Municipal de Assistência Social (CMAS).

Segundo Minayo (2009), entrevista é entendida no sentido de comunicação verbal de informações sobre determinado tema científico. Como fonte de informações, pode fornecer dados construídos no diálogo com o indivíduo entrevistado e a reflexão do próprio sujeito sobre a realidade

\footnotetext{
${ }^{5}$ Neste trabalho, o termo é entendido como o "ato em que alguém concede permissão ou consentimento a um terceiro para falar e agir em seu nome" (DOWBOR et al., 2008, p.15).
} 
que vivencia. Neste estudo, a entrevista aberta permitiu obter informações específicas de cada conselheiro, representante da sociedade civil entrevistado, no que diz respeito a sua entrada no conselho, e nas formas de representatividade.

O roteiro de entrevista foi elaborado pensando-se em questões que buscassem atender aos objetivos da pesquisa e que, também, evitassem influenciar os conselheiros em suas respostas. Dessa forma, foram desenvolvidas questões abertas que fizessem com que os representantes descrevessem como foi o processo de escolha na entidade para se tornar representante, o interesse em participar do CMAS, como era a relação entre o conselheiro e a entidade que representava e se o conselheiro sentia que, efetivamente, representava as demandas e os interesses da comunidade e população local.

Para fazer as entrevistas, foi realizado um primeiro contato com os conselheiros por meio de visitas às reuniões do conselho para explicação do objetivo da pesquisa e para identificar o interesse, ou não, da participação desses conselheiros na pesquisa. Posteriormente, para a realização das entrevistas foi feito o contato direto com os conselheiros por telefone e agendado, com antecedência, os horários e os locais desejados pelos participantes, de acordo com a disponibilidade de cada um. Nesse contato, foi explicado novamente o objetivo do estudo e disponibilizado o Termo de Consentimento Livre e Esclarecido (TCLE), possibilitando maior flexibilidade e conforto para os conselheiros.

Também foram realizadas observações diretas e registro das falas no decorrer das reuniões do Conselho Municipal de Assistência Social (CMAS). A observação direta corresponde a técnica de coleta de dados que permite registrar os acontecimentos no contexto realmente vivido. A observação não consiste apenas em ver e ouvir, mas, também, em examinar fatos ou fenômenos que se desejam estudar. Ajuda a identificar e obter provas a respeito de situações sobre as quais os sujeitos não têm consciência ou não percebem, mas que orientam seu comportamento (MARCONI; LAKATOS, 2007).

As reuniões não foram gravadas, visto que os conselheiros não autorizaram qualquer registro, quer seja em áudio ou fotográfico. Assim, foram monitoradas cinco meses ( 5 reuniões) para registro das falas dos conselheiros e feitas anotações importantes no sentido de marcar a presença dos distintos conselheiros envolvidos em dada conversação. 


\section{REFERENCIAL TEÓRICO}

\section{Representação e Representatividade: diferenças e concepções teóricas}

Nesta seção buscaram-se apresentar os elementos teórico-conceituais sobre as diferenças e concepções teóricas dos termos "representação" e "representatividade", considerando ser importante para a pesquisa, no sentido de se entender como se dá a legitimidade dos conselheiros representantes no Conselho Municipal de Assistência Social.

\section{Democracia e Representação Política}

Anteriormente, foi exposto que a iniciativa de criar os espaços institucionais de participação da sociedade civil nas decisões políticas foi uma reivindicação da população que, até o momento, era pouco representada nos seus interesses e demandas. Com a institucionalização desses espaços, como os Conselhos Gestores de Políticas Públicas, o intuito era de que a sociedade civil tivesse representantes mais próximos do cotidiano da população, tendo, assim, maior representatividade para atuar em nome dos interesses da sociedade.

O termo "democracia" pode se apresentar sob perspectivas diversas, sendo muitas as diferenças e concepções teóricas ${ }^{6}$. Etimologicamente, a palavra "democracia" tem origem grega $($ demos $=$ povo e kratos $=$ poder $)$ e, em sentido amplo, o termo significa "o governo do povo",

Por democracia entende-se uma das várias formas de governo, em particular aquelas em que o poder não está nas mãos de um só ou de poucos, mas de todos, ou melhor, da maior parte, como tal se contrapondo às formas autocráticas, como a monarquia e oligarquia (BOBBIO, 2000, p. 7).

Nas suas diferentes vertentes, enquanto Locke defende a democracia representativa, definida pelo poder que deve ser exercido pelos representantes eleitos pelo povo, Rousseau argumenta, de forma contrária à representação política, propondo a democracia participativa, em que o poder deve ser exercido diretamente pelos cidadãos (BOBBIO, 1998, p. 322). Rousseau (2010) refere-se à representatividade como uma ideia absurda, originária da sociedade civil

\footnotetext{
${ }^{6}$ Dentre estes pensadores destacou-se nesse estudo Bobbio, Locke, Rousseau e outros estudiosos do termo.
} 
corrompida, não podendo haver democracia se essa não for direta, sendo as leis que não forem ratificadas pelo próprio povo consideradas nulas.

A Democracia Direta é caracterizada pela "participação de todos os cidadãos em todas as decisões a eles pertinentes" (ROUSSEAU, 2010, p. 30). Assim, para que exista democracia direta, em que o sujeito participe, ele mesmo, das deliberações que lhes dizem respeito, é preciso que entre os sujeitos deliberantes e a deliberação não exista nenhum intermediário (ROUSSEAU, 2010). $E$ não é isso que acontece nas sociedades, sendo preciso um sujeito ou representante para representar a população, comunidade, bairro ou grupo, pois, como afirma Bobbio (2009), em uma sociedade complexa como a atual, essa forma de democracia é materialmente impossível.

Para que a democracia direta seja considerada uma boa democracia, algumas condições são propostas,

Uma grande simplicidade de costumes que previna a multiplicidade de assuntos e as discussões espinhosas (...) igualdade nas categorias e nas fortunas, sem o que a igualdade não poderia substituir muito tempo nos direitos e autoridade (...) pouco ou nenhum luxo (ROUSSEAU, 2010, p. 71).

Ao contrário disso, a sociedade dos dias atuais é caracterizada pela sua complexidade, diversidade, com múltiplos problemas de difícil solução, o que impossibilita a participação de todos os cidadãos nas deliberações, ou seja, a democracia direta.

Nesse sentido, o próprio autor reconhece a impossibilidade da realização da democracia direta, quando descreve que:

Uma verdadeira democracia jamais existiu nem existiria. É contra a ordem natural que um grande número governe e que o pequeno seja governado. Não se pode conceber que o povo permaneça constantemente junto para se ocupar de negócios públicos, e vê-se facilmente que não poderia estabelecer comissões para isso sem mudar a forma de administração (ROUSSEAU, 2010, p. 71).

Destarte, a partir de Rousseau, a democracia representativa ganha forma como alternativa da democracia direta, na proposta em que o povo deve eleger representantes. Assim, o que existe é a busca do melhor regime possível, que considere os direitos humanos (ROUSSEAU, 2010).

A expressão democracia representativa se refere ao, 
Estado no qual as deliberações políticas são tomadas por representantes eleitos, isto é, as deliberações que dizem respeito à coletividade inteira são tomadas não diretamente por aqueles que delas fazem parte, mas por pessoas eleitas para esta finalidade (BOBBIO, 2009. p.56).

Bobbio (2009) afirma, então, que não é possível dividir a democracia direta e a democracia representativa, como se fossem duas alternativas excludentes, em que uma é escolhida e a outra é descartada. Elas são dois sistemas alternativos, no sentido de que onde existe uma existe a outra, pois cada uma delas pode ocorrer em conformidade com as diversas situações e as diversas exigências, uma vez que são perfeitamente compatíveis entre si.

Assim, democracia direta e democracia representativa podem se integrar reciprocamente, conformando a democracia deliberativa, que diz respeito aos mecanismos de representação política, em que existe o desenvolvimento dos sujeitos, como cidadãos políticos ativos, construtores de consensos, por meio de diálogos interativos realizados no decorrer dos processos de participação, na formulação e elaboração de políticas públicas (GOHN, 2003, p. 42).

A partir dessa discussão, para este trabalho, entende-se que a democracia deliberativa é a que acontece nos Conselhos Gestores de Políticas Públicas, pois, a participação dos conselheiros nas reuniões do conselho se dá na interação, isto é, no diálogo, no qual, a cada palavra de um conselheiro, os demais devem corresponder de forma a discutir o tema em pauta, responder questões, tirar dúvidas, concordar ou discordar.

Além disso, é possível perceber que a democratização do Estado se fortalece por meio da representação da sociedade civil em espaços políticos, por meio dos Conselhos Gestores de Políticas Públicas. Assim, Estado democrático é aquele que luta contra o poder descendente, aquele que vem de cima para baixo, em nome do poder ascendente, que vai de baixo para cima, e contra o poder concentrado em nome do poder distribuído, este último caracterizado como democracia pluralista ${ }^{7}$.

\footnotetext{
7 Uma sociedade pluralista é caracterizada por ser constituída por vários centros de poder. A teoria pluralista toma em consideração o poder monocrático, isto é, o poder concentrado em uma única mão, e sustenta que a solução contra esse tipo de poder é o poder distribuído (BOBBIO, 2009).
} 


\section{Representação e Participação}

Ao refletir sobre "representação e representantes", logo se pensa nos políticos eleitos, como presidente, deputado, prefeito e vereador. No entanto, neste trabalho, foram considerados os representantes que falam em nome de um segmento, como os conselheiros de políticas públicas, que representam a sociedade civil por meio de entidades. Nos Conselhos Gestores de Políticas Públicas, espaços de participação, os representantes da sociedade civil são escolhidos de diversas maneiras para representar a sociedade civil nas suas demandas e interesses (SERAFIM; SANTOS, 2009).

A relação entre participação e representação vem despertando o interesse e a necessidade de tratamento analítico mais aprofundado, uma vez que, na visão de Lüchmann (2008), esses dois instrumentos têm feito predominar um viés dualista em virtude dos diferentes modelos democráticos, pois o primeiro conforma o eixo analítico das teorias da democracia participativa, enquanto o segundo está associado às teorias da democracia representativa.

Considerando o sentido básico de participação (auto representação) e de representação (tornar presente algo que está ausente), fica claro a diferença de cada um nos diferentes modelos democráticos (PITKIN, 1967). De um lado, tem-se que no modelo representativo, a participação fica restrita ao processo eleitoral, enquanto no outro, o modelo participativo, o critério de legitimidade está ancorado na ideia de que as decisões políticas devem ser tomadas por aqueles que estarão submetidos a elas por meio de debate público (LÜCHMANN, 2008).

Com efeito, no plano teórico, as diferenças com relação ao modelo da democracia representativa são marcantes, já que incorpora a participação da população no processo de discussão e de tomada de decisões políticas. Tendo em vista a inevitabilidade da representação (na participação), a efetividade destes princípios de controle social vai ocorrer depõe meio de diferentes práticas de participação e representação (p\&r), cujas características, no tocante à representação, visam a superar os limites da representação eleitoral (LÜCHMANN, 2007, p. 144).

A partir dessa análise, é possível entender que a democracia independente de ser representativa ou participativa, concretiza-se indo além do simples conceito teórico, pois a participação pela representação vai além do simples fato de votar, já que, ao representar, o representante incorpora sua participação no processo de discussões e de tomada de decisões políticas. 
Nesse contexto, a representação no Conselho Municipal de Assistência Social por entidades está ancorada na legitimidade dessas em promover, de diferentes formas, a defesa de variadas causas sociais e demandas de grupos e setores historicamente excluídos dos processos de decisão política. Para Nascimento (2008), essa representação é questão de legalidade; ou seja, vínculo com o Conselho Municipal de Assistência Social, enquanto representatividade, é uma questão de legitimidade.

Assim, a representação legítima requer participação ativa por parte dos representantes e representados (LÜCHMANN, 2008). A representação legítima e inclusiva impõe responsabilidades tanto para os representantes quanto para os cidadãos,

\begin{abstract}
Estes precisam estar dispostos e aptos a mobilizar uns aos outros para participar ativamente tanto do processo de autorização quanto do de prestação de contas. Os representantes devem ouvir essas discussões públicas e as diversas demandas, permanecer conectados com os eleitores e expor as razões de suas ações e avaliações em termos que retomem aquelas discussões. Essa mobilização e essa conectividade podem ser promovidas ou obstadas pelo desenho das instituições representativas (YOUNG, 2006, p. 156).
\end{abstract}

A qualidade e a legitimidade da representação vão depender do grau de articulação e organização da sociedade civil, ou seja, da participação. O que está em jogo nesse conceito de representação é o que se entende por interesses e, ou, desejos. Bobbio (2009) expressa que a democracia deveria ser caracterizada pela representação política, enfatizando que o representante deve buscar os interesses do grupo, da nação, da coletividade, ao contrário da representação dos interesses, em que o representante busca os interesses particulares do representado.

O representante existe para falar em nome de outros sujeitos que, por algum motivo, não podem estar presentes para apresentar suas demandas e seus interesses e, por isso, delegam essa atividade a um sujeito escolhido. Assim, quando um sujeito, ou mesmo um conselheiro, se apresenta como representante de um segmento, espera-se que ele defenda os interesses do coletivo, já que não é possível que todos estejam presentes ou se manifestem. Para isso, é preciso que o representante desenvolva "maneiras de se informar sobre as opiniões do coletivo que representa sobre o tema a ser debatido e decidido, e levar ao coletivo as informações sobre as discussões das quais participa, prestando contas sobre sua atuação" (SERAFIM, SANTOS, 2009, p. 3). 


\section{RESULTADOS E DISCUSSÕES}

\section{Escolha dos representantes e relação representantes e representados}

Essa seção teve por objetivo analisar as características e os desafios de representatividade dos conselhos, considerando a legitimação da autorização e as relações entre representantes e representados. Para isso, foram identificadas as formas de autorização ${ }^{8}$ dos representantes, ou seja, como está sendo legitimada a autorização dada aos conselheiros do CMAS. Foi analisada, também, a relação do representante com o representado, isto é, como se dá a relação do conselheiro com a entidade que representa, analisando se há discussão da pauta antes da reunião, bem como se há a prestação de contas após as reuniões, no que diz respeito às políticas de assistência social. Além disso, foi identificado os temas previstos nas pautas das reuniões e qual o conselheiro que sugeriu a inserção de determinado tema.

O CMAS é composto de representantes da sociedade civil e do poder público. A representação do segmento da sociedade civil no CMAS se dá por meio de entidades. Para a entidade ter assento, com poder de voto no CMAS, ela precisa estar registrada no conselho como entidade de usuários ou de defesa de direitos dos usuários de assistência social; entidade prestadora de serviços da área de assistência social; e entidade de trabalhadores da área de assistência social (FIG. 1).

As atividades e programas de assistência social no município são executadas pelo poder público local, por intermédio da Secretaria Municipal de Política Social e pelas 28 entidades da sociedade civil registradas no Conselho Municipal de Assistência Social. Dessas, as entidades que tiveram representantes no conselho no período da pesquisa foram: APAE, APAS, CEI MARIA TEREZA, C.E.R.C. CHAVES, REBUSCA, CTA, APONE, AVIRC e NASVIR. Uma vez que essas entidades obtêm assento no CMAS, elas passam a ter autorização para falar em nome dos interesses dos que estão ausentes.

\footnotetext{
${ }^{8}$ Neste trabalho, o termo é entendido como o "ato em que alguém concede permissão ou consentimento a um terceiro para falar e agir em seu nome" (DOWBOR et al., 2008, p.15).
} 
Figura 1 - Composição do Conselho Municipal de Assistência Social, Viçosa/MG

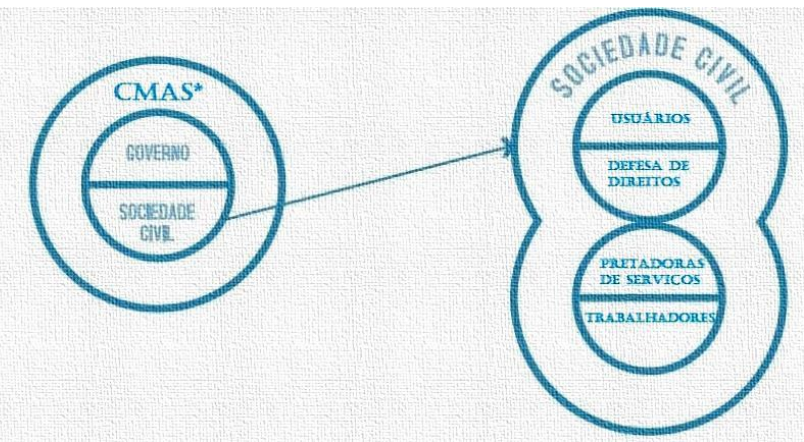

Fonte: Adaptado dos autores Dowbor et al. (2008).

O representante é escolhido para falar em nome de outros sujeitos que, por algum motivo, não podem estar presentes, para apresentar suas demandas e seus interesses e, por isso, confiam essa atividade a um sujeito escolhido. Assim, quando o conselheiro se apresenta como representante de uma entidade, organização ou usuário, espera-se que ele defenda os interesses do coletivo, já que não é possível que todos estejam presentes ou se manifestem (SANTOS; SERAFIM, 2009).

Ao analisar a composição do CMAS, identifica-se que não existe norma que prevê as entidades que irão compor o CMAS. Desse modo, o Regimento Interno estabelece que seja nomeada uma Comissão responsável para o processo de escolha das entidades e, assim, as entidades, que têm assento no CMAS, são eleitas em foro próprio. Nesse caso, é a entidade quem indica qual de seus membros integrará o CMAS, assim, o conselho não tem intervenção nenhuma nesse processo de escolha. De acordo com essas informações, percebe-se que há o processo eleitoral específico para a seleção das entidades, mas não há forma compartilhada de escolha dos representantes entre essas entidades, o que acaba induzindo que cada uma desenvolva processo diferente.

Assim, para um sujeito se tornar representante, existem diversas formas de autorização utilizadas pelas entidades, que não necessariamente aquela realizada por meio de eleição. Os autores Serafim e Santos (2009) destacam a "representação autorizada", que diz respeito a diversas formas de autorização de representantes, seja eleitoral, seja porque os representados pensam que é o sujeito mais adequado para representá-los, ou porque sabe atuar em nome do grupo ou sabe negociar, é parte daquele grupo ou é filiado. 
No caso do Conselho Municipal de Assistência Social (CMAS), ao ser identificada a forma de escolha utilizada pelas entidades para a seleção dos conselheiros da sociedade civil, constatou-se que dos dez representantes da sociedade civil, seis $(60 \%)$ foram escolhidos por meio de indicação, enquanto três (30\%) foram escolhidos pelo processo eleitoral (FIG. 2).

Figura 2 - Forma de escolha dos conselheiros da sociedade civil pelas entidades que representam, Viçosa/MG.

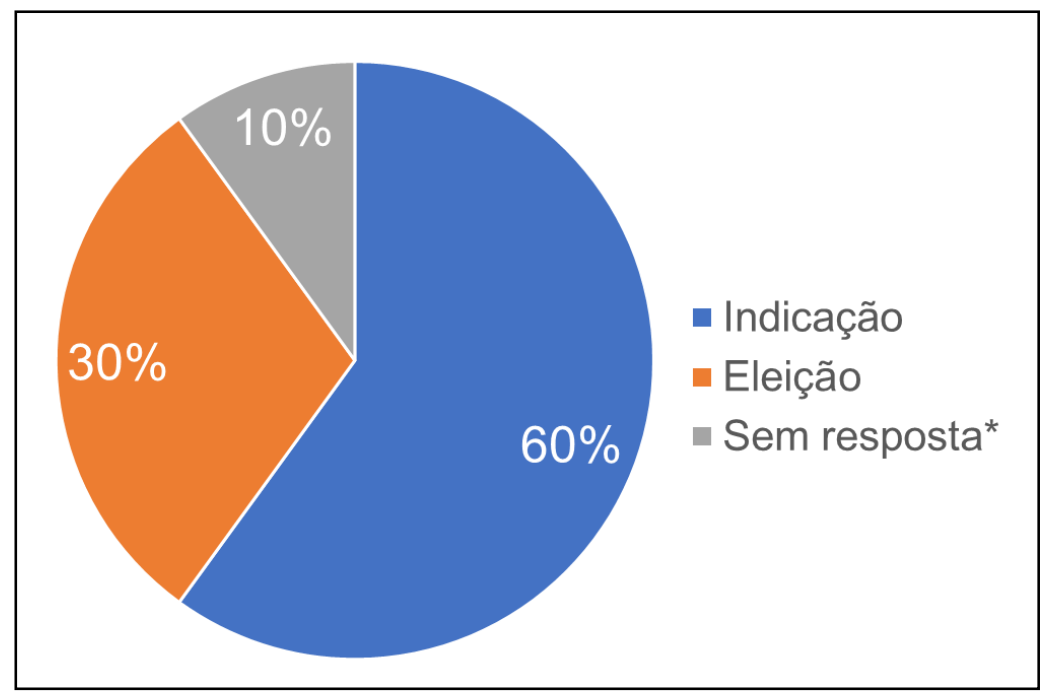

Fonte: Dados da Pesquisa, 2015.

* Não foi possível obter os dados sobre a ocupação principal de um conselheiro, pois esta informação não foi encontrada no CMAS, e, durante a pesquisa, o mesmo veio a óbito.

Observou-se, então, que a escolha por indicação é a forma mais utilizada pelas entidades que têm assento na assistência social. Assim, é importante destacar que a maioria dos representados não participa diretamente da escolha dos seus representantes, uma vez que não existe processo eleitoral específico, sendo a seleção dos conselheiros feita por meio de indicação pela entidade ou sua diretoria, ou mesmo pela obrigação em estar no conselho.

Sobre isso, a autora Kiyota (2007) afirma que,

mesmo que esta forma de indicação indireta possa, em alguns caso, acabar expressando o consenso dos representados, sobre quais pessoas deveriam representá-los, e que a eleição não seja um instrumento suficiente para que ocorra a responsabilização social, esta ausência de algum procedimento que amplie a participação dos representados na seleção do representante faz com que se perca a oportunidade de se debater o espaço propriamente dito e a função deste componente neste espaço, dificultando análises futuras, tanto do espaço de participação, como da atuação deste ator como representante (KIYOTA, 2007, p. 158). 
As falas dos representantes do CMAS comprovam o argumento dos autores. Ao indicar uma representatividade, que se constrói no interior de cada entidade, pois, como demonstram os dados, as entidades que tiveram representantes no CMAS se deram em virtude de várias motivações, como confirma os relatos abaixo,

Por estar cursando na época a Faculdade de Serviço Social. Para entender melhor como funciona o SUAS - Sistema Único de Assistência Social e a LOAS - Lei Orgânica de Assistência Social (C1).

A entidade está diretamente ligada à Assistência Social e assim acho interessante participar para saber o que acontece (C2).

Para colaborar mais com a instituição na qual exercia funções como voluntário. Para adquirir maior conhecimento da legislação referente à assistência social, visando atender às suas exigências e, ao mesmo tempo, acompanhar e avaliar a administração municipal neste aspecto (C3).

Tinha que participar. No início, foi por obrigação, depois comecei a gostar (C7).

Pela necessidade de defender a entidade no conselho, pois se tinha uma visão muito assistencialista, de doações (C4).

Porque, como representante da instituição onde trabalhava, seria interessante estar presente neste conselho. Por causa da instituição (C5).

Acredito na mudança através da participação (C6).

Entretanto, nos relatos dos representantes foi possível perceber que a sua inserção no CMAS se deve, principalmente, para representar a sua entidade, seja por interesse, seja para colaborar com ou defender a sua entidade, ou seja, por obrigação. Esse é um dado interessante, uma vez que demonstra atuação comprometida do conselheiro para com os objetivos da entidade que representa, possibilitando a defesa de interesses particulares de cada entidade.

No entanto, essa representação diretamente relacionada aos interesses particulares de cada entidade faz com que os conselheiros se esqueçam do segmento que realmente representa, ou seja, a sociedade civil.

Nessa perspectiva Lacerda (1997) justifica,

a representatividade significa que os conselheiros devem atuar de acordo com as demandas do grupo ou entidade que representam, ampliando seu espaço de atuação para toda a sociedade, sem se distanciar do movimento que o indicou. Quanto à legitimidade, assinala 
que os conselheiros devem ser indicados pelas entidades ou movimentos a que pertencem, mediante ampla discussão interna e com outros movimentos, na garantia de que essa indicação represente - de fato - as necessidades e vontades dessas pessoas e a capacidade de consensos pelo diálogo e pela negociação (LACERDA, 1997 apud WENDHAUSEN; BARBOSA; BORBA, 2006, 138).

Além disso, foi possível identificar que dos quatro representantes de usuários, um „é membro da entidade que representa. De acordo com Cunha (2009), esse fato evidencia a fragilidade da participação desse segmento, seja diretamente, seja por meio de suas organizações.

Em tese, as entidades que escolhem seus representantes por meio do processo eleitoral seriam mais democráticas em relação às entidades que fazem isso por meio de indicação (AVRITZER; ALMEIDA, 2009). No entanto, a autora Urbinati (2006) apresenta uma nova concepção ao propor novo olhar sobre a representação.

A autora considera que, embora a autorização eleitoral tenha importância fundamental para legitimar a representação, ela não diz muito a respeito da verdadeira natureza da política representativa na sociedade democrática (URBINATI, 2006), tendo, então, sido complementada por formas "não eleitorais", mas legítimas, de exercício da atividade de representar (AVRITZER, 2007, p. 453-454).

Como destacam Lavalle, Houtzager e Castello (2006, p. 43),

\begin{abstract}
como as organizações civis estão a desempenhar de facto e de jure um novo papel ativo na representação política, e tal papel é diferente ao desempenhado por partidos e sindicatos, isso cria dilemas acerca da sua representatividade. Em contraste com tais instituições, a grande maioria das organizações não utiliza mecanismos eleitorais para estabelecer sua representatividade, nem funciona sob a lógica de afiliação (...). Não existem modelos decantados histórica ou teoricamente para pensar como organizações civis podem construir uma representatividade de índole política por fora de tais mecanismos (LAVALLE; HOUTZAGER; CASTELLO, 2006, p. 43).
\end{abstract}

Verifica-se que, mesmo que a eleição seja considerada o meio formal utilizado para a escolha dos representantes dos cargos públicos, ou mesmo dos Conselhos Gestores de Políticas Públicas, outros mecanismos de autorização também podem ser utilizados para legitimar a representação nos espaços de participação.

Embora a forma de escolha dos conselheiros do CMAS seja importante para a legitimidade da sociedade civil, a representação não pode ser considerada somente pelo processo de autorização, pois, como afirma Macedo (2013), esse é um aspecto formal da representação, que 
indica apenas o consentimento dos representados para os representantes, não vinculando, porém, as decisões dos representantes ao interesse dos representados. Sendo assim, o próximo passo foi analisar a relação entre representante e representado, ou seja, a relação estabelecida entre os conselheiros da sociedade civil com suas entidades, as quais representam.

A crítica comum apresentada por diferentes autores (ABERS; KECK, 2008, TATAGIBA, 2002) diz respeito ao fato de que os representantes da sociedade civil apresentam fragilidade no vínculo entre representantes e representados. Isso vai contra a representatividade do segmento, pois, de acordo com Tatagiba (2002), quanto mais forte essa relação, maior a possibilidade de que diferentes interesses possam, de fato, se fazer representar no conselho.

Tabela 1 - Mecanismos de comunicação entre conselheiro e entidade, Viçosa, MG

\begin{tabular}{lccccc}
\hline & Sim & Não & Às vezes & $\begin{array}{c}\text { Sem } \\
\text { resposta }\end{array}$ & Total \\
\hline Consulta & 0 & $6(60 \%)$ & $3(30 \%)$ & $1(10 \%)$ & $10(100 \%)$ \\
\hline Informa & 0 & $5(50 \%)$ & $4(40 \%)$ & $1(10 \%)$ & $10(100 \%)$ \\
\hline
\end{tabular}

Fonte: Dados da Pesquisa, 2015.

De maneira geral, os dados demonstram que os conselheiros representantes da sociedade civil do Conselho Municipal de Assistência Social (CMAS) não têm tido o acompanhamento de sua atuação por parte das entidades que representam. Mais da metade, seis conselheiros $(60 \%)$ não consultam a entidade que representam antes da reunião, enquanto três $(30 \%)$ dizem que, às vezes, fazem contato com a entidade (TAB. 1).

Essa prática reforça o comprometimento com a defesa dos interesses particulares da sua entidade no espaço de interesses coletivos que se espera que seja o conselho. $O$ trecho a seguir, extraído da transcrição da fala de um conselheiro, mostra claramente esta situação. Esse fato tem acontecido por diferentes motivos, como apresentado nas falas abaixo:

Geralmente, não há tempo ou disponibilidade de tempo dos envolvidos no assunto para uma reunião prévia; quando necessário há contatos telefônicos (C3).

Não (não tem comunicação). No início havia uma troca sim, pelo fato da entidade ter tido muita dificuldade de se inserir na assistência social. Atualmente não, pois as discussões são mais específicas (C4).

Não existe comunicação. Quando necessário sim, depois da reunião (C6). 
A partir das falas apresentadas foi possível perceber que as decisões do CMAS não são repassadas para as entidades que os conselheiros representam, assim como as entidades não são consultadas antes das reuniões, possibilitando discussão antecipada e, consequentemente, decisão que de fato legitime as decisões. De acordo com Tatagiba (2002), isso acaba levando à baixa representação do conselho, que, apesar da sua legalidade, não consegue legitimar a representatividade dos representantes em relação aos representados.

Dessa forma, os conselheiros tendem a defender, no conselho, suas próprias opiniões e não as propostas e posicionamentos resultantes da discussão com as entidades, sendo então, que, muitas decisões importantes não são de fato decididas em coletividade, estando sob influência apenas dos representantes (TATAGIBA, 2002). Num regime democrático os representantes não devem afastar do cotidiano da sociedade, devendo estar, permanentemente, em contato com os cidadãos, mantendo relação contínua (URBINATI, 2005).

Assim, quando o representante se coloca no papel de falar em nome de outros, ele deve representar, não sua opinião individual, mas a do coletivo, do segmento a que representa. Para isso, ele precisa desenvolver maneiras de se informar sobre as opiniões do seu segmento, sobre o tema a ser debatido e decidido, e levar a eles as informações sobre as discussões das quais participa, prestando contas da sua atuação. Contudo, os representados também precisam subsidiar os representantes com informações, opiniões e discussões realizadas naquele grupo e cobrar deles quanto à sua atuação (SERAFIM; SANTOS, 2009).

Alguns autores têm definido essa falta de vínculo entre representantes e representados como uma crise de representação política, que acaba causando descontentamento com a democracia e suas instituições, intensificado pela falta de atendimento das demandas da sociedade (BOBBIO, 2009, COSTA, 2007, MANIN, 1998, NOGUEIRA, 1998 apud SOUZA, 2012).

$O$ representante deve defender os interesses do seu segmento, sem deixar de reconhecer as necessidades e demandas dos outros segmentos. A representação requer equilíbrio entre os interesses representados, a capacidade de negociação no conselho e o bem maior. "A verdadeira democracia reside no reconhecimento de outros grupos, suas necessidades e legitimidade como cidadãos" (SERAFIM; SANTOS, 2009, p. 4).

Ao analisar as atas e as deliberações das reuniões do CMAS, foi possível delimitar as temáticas propostas e indícios da forma de participação e representatividade dos conselheiros para 
atendimento às demandas e aos interesses da população (TAB. 2). Assim, os temas que compõem a agenda, bem como quem (qual segmento) a propõe, indicam a representatividade dos conselheiros.

Apesar de o Regimento Interno estabelecer que a pauta das reuniões fosse definida e organizada pela Mesa Diretora (considerando que a mesa diretora é paritária), juntamente com a Secretaria Executiva, estando aberta a modificações pelos demais conselheiros, os dados demonstram que é o poder público que mais detém a capacidade de agenda do CMAS.

Tabela 2 - Deliberações prevalentes no CMAS

\begin{tabular}{|c|c|c|c|c|c|c|}
\hline & Jul. & Ago. & Set. & Out. & Nov. & Total \\
\hline Regimento Interno & & $\mathrm{X}$ & & & & 1 \\
\hline Demonstrativo Financeiro/2014 & $\mathrm{X}$ & & & $\mathrm{X}$ & & 2 \\
\hline Convênios & & & & $x$ & & 1 \\
\hline Subvenção & $\mathrm{x}$ & $\mathrm{X}$ & $\mathrm{X}$ & $\mathrm{X}$ & $\mathrm{X}$ & 5 \\
\hline Superávit & $x$ & $\mathrm{X}$ & & & & 2 \\
\hline $\begin{array}{l}\text { Programas e projetos da Assistência } \\
\text { Social }\end{array}$ & & & $\mathrm{X}$ & & $X$ & 2 \\
\hline CRAS/CREAS & & & & $\mathrm{X}$ & & 1 \\
\hline SUAS & $x$ & $\mathrm{X}$ & & & & 2 \\
\hline Formação de Comissões & $x$ & $x$ & $\mathrm{x}$ & & $\mathrm{X}$ & 4 \\
\hline CNEAS (cadastro de entidades) & $\mathrm{X}$ & $\mathrm{X}$ & $\mathrm{X}$ & & & 3 \\
\hline Proposta & $\mathrm{X}$ & & & & & 1 \\
\hline Eleição & $\mathrm{X}$ & $\mathrm{X}$ & & $\mathrm{X}$ & & 3 \\
\hline Conferências & $x$ & $\mathrm{x}$ & $x$ & & & 3 \\
\hline Encaminhamento de documento & & & $\mathrm{X}$ & & & 1 \\
\hline Visita às entidades & & & & & $\mathrm{X}$ & 1 \\
\hline Processo seletivo ou concurso público & & $\mathrm{X}$ & & & $\mathrm{X}$ & 2 \\
\hline Demandas da comunidade & & & & & & 0 \\
\hline Textos para reflexão & & & $\mathrm{X}$ & & & 1 \\
\hline Agradecimentos & & & $x$ & $\mathrm{X}$ & & 2 \\
\hline Publicação das atas & & & & & $\mathrm{X}$ & 1 \\
\hline Licitações & & $x$ & $x$ & & & 2 \\
\hline Infraestrutura & & $x$ & & & $\mathrm{X}$ & 2 \\
\hline Avanços e conquistas & & $\mathrm{x}$ & & $\mathrm{X}$ & & 2 \\
\hline
\end{tabular}

Fonte: Dados da pesquisa, 2015.

Os dados da TAB. 2 mostram que os temas que mais aparecem na pauta estão relacionados com as questões de organização e funcionamento do CMAS, como subvenção, seguida da nomeação de comissões temáticas, cadastro de entidades, eleição dos conselheiros e conferência municipal. Uma possível explicação para o predomínio dos dois últimos temas pode estar 
relacionada com o fato de que a gestão 2013/2015 estava finalizando no mês de setembro e era necessário nomear novos conselheiros, sendo, também, o atual ano para a realização da conferência municipal. Os dados apresentados evidenciam que o poder público tem maior capacidade de agenda e consequente representatividade no CMAS, pois não existe nenhum tema inserido pelos conselheiros ou por sujeitos externos, no que diz respeito a demandas tanto das entidades quanto da sociedade civil.

A não inserção de temas pode estar relacionada com a baixa representatividade dos conselheiros do CMAS, diferente do estudo realizado por Cunha (2009), em que a sociedade civil via o Conselho Municipal de Assistência Social, como canal para se ter algum acesso às instâncias governamentais, seja para obter informações ou realizar demandas e denúncias, seja por não existir outra forma de participação social e interação.

$\mathrm{Na}$ maioria das vezes, os conselheiros estão subordinados às demandas pontuais e emergenciais das secretarias municipais, principalmente relacionadas aos procedimentos e prazos necessários à realização de convênios com programas estaduais e federais. A prevalência de questões administrativas pontuais é resultado da ausência de um planejamento das ações dos Conselhos que possa prever a agenda de discussões, o período das ações e seus respectivos impactos a curto, médio e longo prazo (SANTOS, 2002, p. 18-19).

Para Santos (2002), talvez o maior desafio dos conselhos esteja em criar dinâmica de funcionamento que permita aos conselheiros estabelecer agenda de decisões que não esteja subordinada à pauta da administração pública.

\section{CONCLUSÃO}

A democracia tende a incorporar novas concepções inerentes à participação da sociedade civil nas decisões políticas. A partir dos autores discutidos, foi possível entender que diante de uma sociedade complexa e dinâmica, como a atual, não é possível que todos os cidadãos participem das decisões políticas, sendo a democracia representativa uma alternativa de participação. Assim sendo, não se pode entender a participação e a representação separadamente, já que não existe dualidade entre os termos e, na prática, elas se complementam.

É importante pensar que a representação vai além da simples escolha dos conselheiros do Conselho Municipal de Assistência Social, seja por eleição, seja por indicação, pois é indispensável 
considerar também a representatividade no que diz respeito à relação entre representante e representado.

A realidade do CMAS mostra que a participação se constrói no interior de cada entidade, pois conforme os resultados comprovam, os mecanismos de autorização reconhecidos pelas entidades se deram por diferentes formas e motivações. Este fato caracteriza processo legítimo do exercício de representar, porém compromete a atuação do conselheiro que acaba sendo influenciado pelas preferências de determinado grupo e não da sociedade civil em geral.

Completamos que, o CMAS não consegue legitimar a representatividade dos representantes em relação aos representados, uma vez que não existe discussão antes das reuniões, bem como as decisões não são repassadas para as entidades que os conselheiros representam, o que não condiz com espaço coletivo. Nesse sentido, a fragilidade do CMAS se destaca em legitimar o contato permanente com o seu segmento e desenvolver maneiras de se informar sobre a opinião, bem como levar a eles as informações sobre as discussões do conselho.

Por fim, é evidente que os interesses e as decisões da política de assistência social são influenciados pelas preferências de determinados grupo e se concentram nas mãos dos gestores, pois as pautas das reuniões, na maioria das vezes, abordam demandas do poder público, não apresentando temas inseridos pelos conselheiros ou por sujeitos externos.

\section{REFERÊNCIAS}

ABERS, Rebecca Neaera; KECK Margaret, E. Representando a diversidade: Estado, sociedade e "relações fecundas" nos conselhos gestores. Cadernos CRH, Salvador, v. 21, n. 52, p. 99-112, 2008. Google crosssef

AVRITZER, Leonardo. Sociedade civil, instituições participativas e representação: da autorização à legitimidade da ação. Revista de Ciências Sociais, Rio de Janeiro, v. 50, n. 3, p. 443-464, 2007. Google Ecrosser

; ALMEIDA, Debora Cristina de. Participação e $(R e)$ distribuição nas Políticas Públicas em Minas Gerais. Relatório de Pesquisa. Belo Horizonte: UFMG, 2009.

BOBBIO, Norberto. Dicionário de política. Brasília: UnB, 1998. Google

O Futuro da Democracia: uma defesa das regras do jogo. Rio de Janeiro, Paz e Terra, 6. edição, 2009. Google 
. Teoria geral da política: a filosofia política e as lições dos clássicos. Trad. Daniela Beccaccia Versiani. 6. edição. Rio de Janeiro: Campus, 2000. Google

CUNHA, E. S. M. Efetividade deliberativa: estudo comparado de Conselhos de Assistência Social (1997/2006), 2009. 371 f. Tese (Doutorado em Ciência Política), Faculdade de Filosofia e Ciências Humanas, Universidade Federal de Minas Gerais, Belo Horizonte, 2009. [Visualizar] Google

DOWBOR, Monika; HOUTZAGER, Peter; SERAFIM, Lizandra. Enfrentando os desafios da representação em espaços participativos. São Paulo: CEBRAP: IDS, 2008. [Visualizar] Google

GOHN, Maria da Glória. Conselhos Gestores e Participação sociopolítica. 2. ed. Cortez Editora, São Paulo, 2003.

KIYOTA, Norma. A representação dos agricultores familiares em espaços institucionais de participação social no Sudoeste do Paraná, 2007. 204 f. Tese (Doutorado em Desenvolvimento Rural), Faculdade de Ciências Econômicas, Universidade Federal do Rio Grande do Sul, Porto Alegre 2007. [Visualizar] Google

LAVALLE, Adrián Gurza; HOUTZAGER, Peter; CASTELLO, Graziela. Representação política e Organizações civis. Novas instâncias de mediação e os desafios da legitimidade. Revista Brasileira de Ciências Sociais, v. 21, n. 60, p. 115-168, 2006. [Visualizar] Google

LÜCHMANN, Lígia Helena Hahn. A representação no interior das experiências de participação. Lua Nova: Revista e cultura política, São Paulo, n. 70, p. 139-221, p. 2007. [Visualizar] Google

LÜCHMANN, Lígia Helena Hahn. Participação e representação nos conselhos gestores e no orçamento participativo. Cadernos CRH, Salvador, v. 21, n. 52, p. 87-97, 2008. [Visualizar] Google

MACEDO, Nayara. Democracia ao avesso: a relação entre representação e a promoção de desigualdades no Estado Democrático de Direitos. Revista Simbiótica, Ufes, v. Único, n.5, 2013. Google

MARCONI, Marina de Andrade; LAKATOS, Eva Maria. Metodologia Científica. São Paulo: Atlas, p. 77-142, 2007.

MINAYO, Maria Cecília de Souza. Pesquisa social: teoria, método e criatividade. 29. Ed. Petrópolis, RJ: Vozes, 2009.

NASCIMENTO, Amauri Mascaro. Compêndio de Direito Sindical. 5. ed. São Paulo: LTr, 2008.

PITKIN, H. F. The concept of representation. Berkeley: University of California Press, 1967.

ROUSSEAU, Jean-Jacques. O contrato social. Porto Alegre: L\&PM, 2010. 
SANTOS, Mauro Rego Monteiro dos. Conselhos municipais e a participação cívica na gestão das políticas públicas: o caso da metrópole fluminense. Caderno Metrópole, n. 07, p. 97-112, 2002. Google

SERAFIM, Lizandra; SANTOS, Agnaldo dos. Representação e representatividade nos espaços de participação. Instituto Pólis, 2008. [Visualizar] Google

SOUZA, Cláudio André de. Pensar a democracia: desafios e reflexões sobre a representação política na contemporaneidade. Pindorama: Revista Eletrônica Científica do IFBA, v. 1, n. 2, p. 121, 2012. [Visualizar] Google

TATAGIBA, Luciana. Os Conselhos gestores e a democratização das políticas públicas no Brasil. In: DAGNINO, Evelina. (Org.) Sociedade civil e espaços públicos no Brasil. Rio de Janeiro: Paz e Terra, p. 47-103, 2002.

URBINATI, Nadia. O que torna a representação democrática? Revista Lua Nova, São Paulo, v. 67, n. 67, p. 191-228, 2006. [Visualizar] Google

WENDHAUSEN, Águeda L. P.; BARBOSA, Tatiane Muniz; BORBA, Maria Clara de. Empoderamento e recursos para a participação em conselhos gestores. Saúde e Sociedade, v. 15, n. 3, p.131-144, set-dez 2006. [Visualizar] Google

YOUNG, Marion Iris. Representação política, identidade e minorias. Revista Lua Nova, São Paulo, v. 69 , p. 139-190, 2006. [Visualizar] Google 